\title{
Triboluminescence and Selective Hydrogen-Bond Responsiveness of Thiochromanone Derivative
}

Liangwei Ma, Bingbing Ding, Zhiyi Yuan, Xiang Ma* and He Tian

Key Laboratory for Advanced Materials and Feringa Nobel Prize Scientist Joint Research Center, Frontiers Science Center for Materiobiology and Dynamic Chemistry, School of Chemistry and Molecular Engineering, East China University of Science \& Technology, Shanghai 200237, China. E-mail: maxiang@ecust.edu.cn

General. ${ }^{1} \mathrm{H}$ NMR spectra were measured on a Bruker AV-400 spectrometer. The electronic spray ionization (ESI) high-resolution mass spectra were tested on a Waters LCT Premier XE spectrometer. The UV-Vis absorption spectra were obtained on a PerkinElmer Lambda 950 spectrophotometer. Emission spectra were recorded on an Agilent Cary Eclipse spectrophotometer. Absolute PL quantum yields were determined with a spectrometer C11347-11 (Hamamatsu, Japan). X-ray diffraction experiments were carried out on Bruker D8 Venture diffractometer with a PHOTON $100 \mathrm{CMOS}$ area detector, using Mo-K radiation from an Incoatec I $\mu$ S micro source with focusing mirrors. Density functional theory (DFT) and time-dependent (TD) DFT calculations were performed with the Gaussian 09 (Revision E.01) software package. The ground-state $\left(\mathrm{S}_{0}\right)$ geometries were optimized with the B3LYP and 6-311+G(d,p) basis. The excitation energies in the singlet and triplet states were obtained using the time-dependent (TD) DFT method based on the optimized $\mathrm{T}_{1}$ molecular structure. 4Aminobenzenethiol, ethyl 3-bromopropanoate, 3-methylbutan-2-one, and compounds HTO were purchased from Adamas. Compounds TDI and MeTO was obtained according to our previous report. ${ }^{1}$ All solvents were obtained commercially and used as supplied without further purification. Video S1 and S2 was taken under dark and daylight, respectively. 


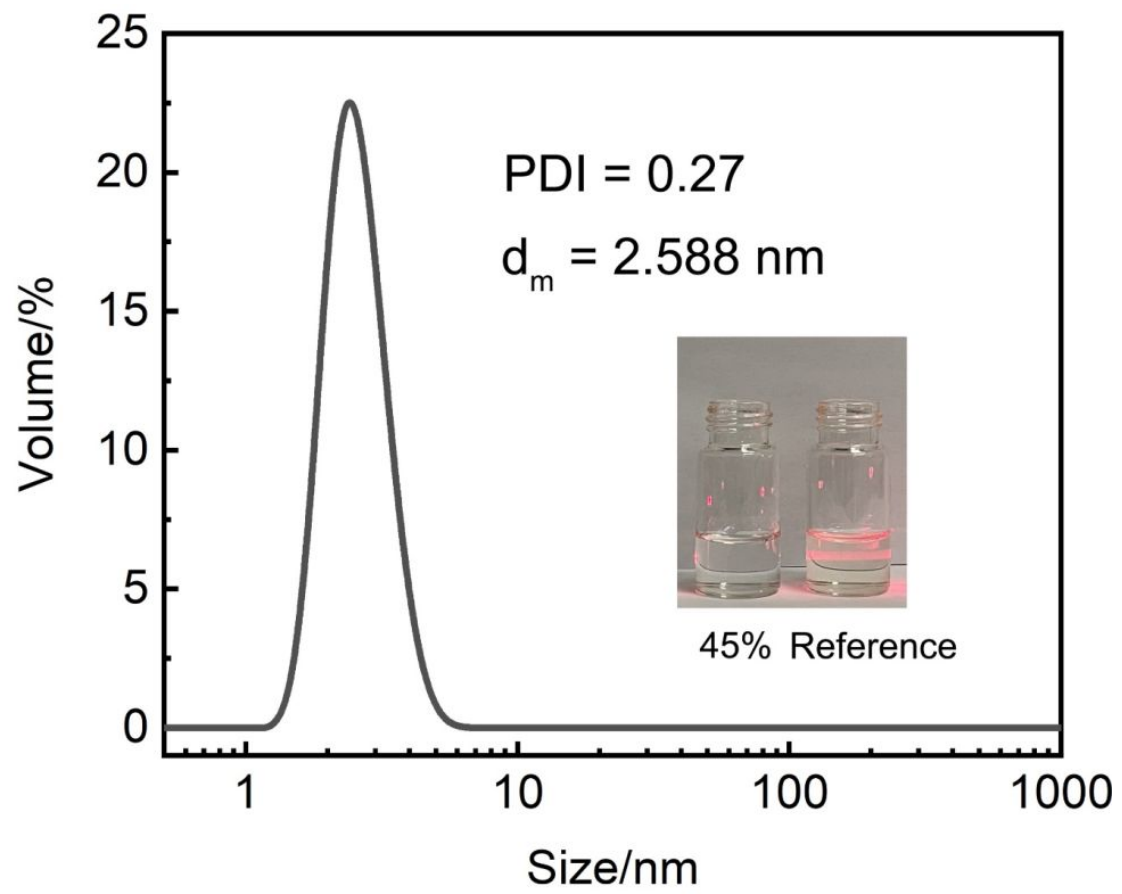

Figure S1. Dynamic light scattering (DLS) spectra of the THF solution of TDI with $45 \%$ water fraction; Inset: photograph of the THF solution of TDI with $45 \%$ water fraction (Left) and a silica (5 wt.\%) solution in water irradiated by laser under daylight.

Table S1. The Maximum emission wavelength and photoluminescence quantum yield of TDI in different solvents.

\begin{tabular}{ccc}
\hline Solvent & $\boldsymbol{\lambda}_{\text {em }} / \mathbf{n m}$ & $\boldsymbol{\Phi}_{\mathbf{P L}} / \mathbf{o}$ \\
\hline EtOH & 465 & 9.36 \\
DCM & 427 & 0.46 \\
MeOH & 469 & 12.17 \\
Toluene & 414 & 0.27 \\
MeCN & 427 & 2.13 \\
Propanol & 462 & 8.71 \\
DMF & 425 & 2.02 \\
Propylamine & 423 & 2.88 \\
\hline
\end{tabular}




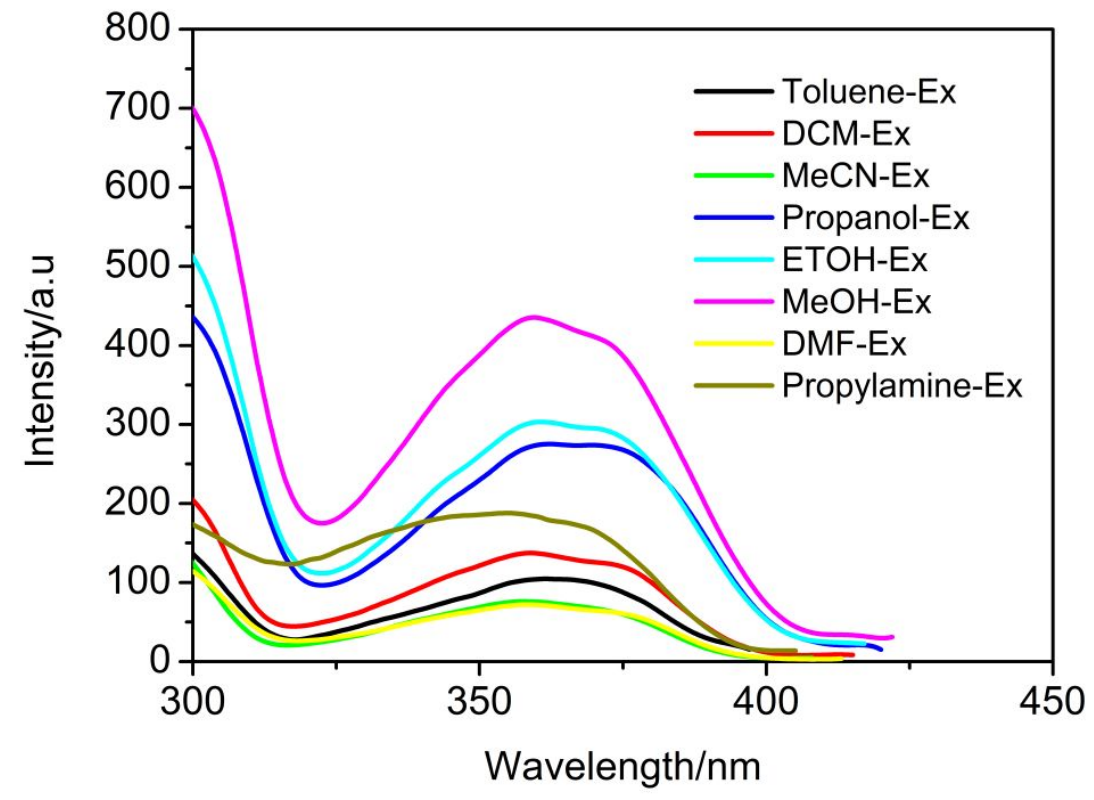

Figure S2. Excitation spectra of TDI in the different solvent; $\mathrm{C}=5 \times 10^{-5} \mathrm{M}$<smiles>O=C1CCSc2ccccc21</smiles><smiles>COc1ccc2c(c1)C(=O)CCS2</smiles>

HTO

MeTO

Scheme S1. Chemical structure of HTO and MeTO. 

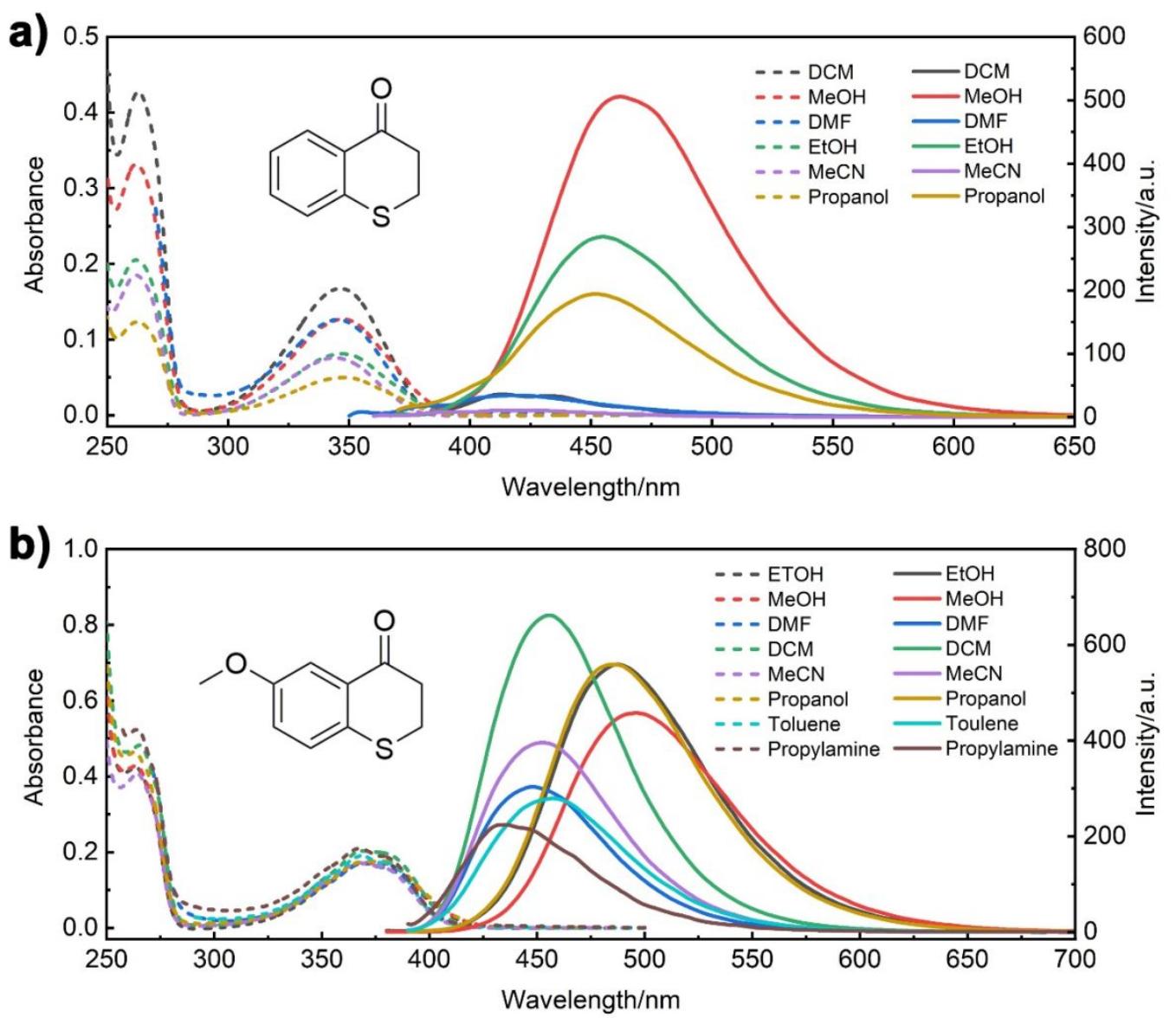

Figure S3. Absorption (dash line) and emission (solid line) of HTO (a) and MeTO (b) in different solvents. $\mathrm{C}: 5 \times 10^{-5} \mathrm{M} ; \lambda_{\mathrm{ex}}=350 \mathrm{~nm}$.

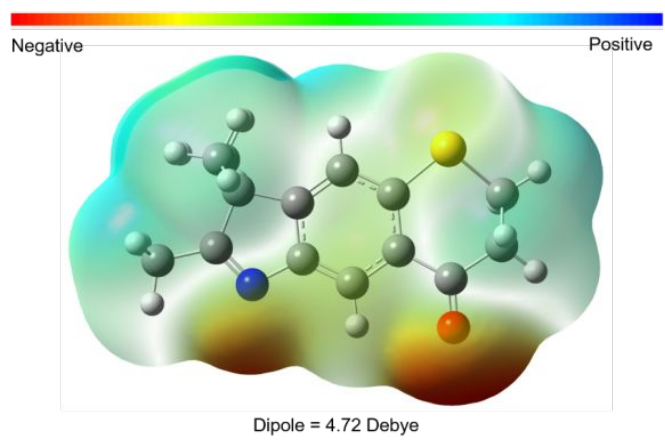

Figure S4. Electrostatic potential of electron density at B3LYP/6-311+G(d,p) level.

Table S2. Single crystal data of TDI.

\begin{tabular}{ll}
\hline Name & TDI \\
\hline
\end{tabular}




\begin{tabular}{|c|c|}
\hline Formula & $\mathrm{C}_{14} \mathrm{H}_{15} \mathrm{NOS}$ \\
\hline Wavelength & $0.71073 \AA$ \\
\hline \multirow[t]{2}{*}{ Space group } & $\mathrm{P} 21 / \mathrm{n}$ \\
\hline & $\mathrm{a}=11.6412(3)$ \\
\hline \multirow[t]{3}{*}{ Cell Lengths $(\AA)$} & $b=10.0417(3)$ \\
\hline & $\mathrm{c}=11.9547(3)$ \\
\hline & $\alpha=90$ \\
\hline \multirow[t]{2}{*}{ Cell Angles $\left(^{\circ}\right)$} & $\beta=111.8820(10)$ \\
\hline & $\gamma=90$ \\
\hline Volume $\left(\AA^{3}\right)$ & 1301.91(7) \\
\hline $\mathrm{Z}$ & 4 \\
\hline Density $\left(\mathrm{Mg} / \mathrm{m}^{3}\right)$ & 1.252 \\
\hline $\mathrm{F}(000)$ & 520 \\
\hline $\mathrm{h}_{\max }, \mathrm{k}_{\max }, \mathrm{l}_{\max }$ & $14,12,13$ \\
\hline $\begin{array}{l}\text { max. and min. } \\
\text { transmission }\end{array}$ & 0.7456 and 0.5949 \\
\hline CCDC & 2070589 \\
\hline
\end{tabular}

\section{Reference}

1. L. Ma, S. Sun, B. Ding, X. Ma and H. Tian, Adv. Funct. Mater., 2021, 31, 2010659. 